\title{
Configuring School Image Assets of Colleges in Taiwan
}

\author{
Chia Kun Lee ${ }^{1, *}$, Hsin Chu Chen ${ }^{2}$ \\ ${ }^{1}$ Department of Mass Communication, I-Shou University, Taiwan \\ ${ }^{2}$ Department of Public Relations and Advertising, Kun Shan University, Taiwan
}

Copyright $\bigcirc 2018$ by authors, all rights reserved. Authors agree that this article remains permanently open access under the terms of the Creative Commons Attribution License 4.0 International License

\begin{abstract}
Higher education in Taiwan faces various challenges, such as the low-birth rate, blurred positioning, and lack of marketing concepts. In order to sustain, more effect strategies and actions resource should be implemented to enhance service of the colleges and universities. Therefore, image asset management becomes a critical start. This study aims to identify the image asset management indicators by applying the modified Delphi technique and the analytic hierarchy process. These two methods can retrieve the critical factors out of literature, and configure how they were operated. The study finally developed a three-layer framework of college image asset management, including 5 dimensions, 13 sub-dimensions, and 77 indicators. According to the participants' perspectives, the dimensions of the stakeholder image and student image were on the top priority. Next, among the sub-dimensions, the internal stakeholder image and the brand image had higher priority than the rest.
\end{abstract}

Keywords Image Assets, Higher Education, Modified Delphi, AHP

\section{Background}

\subsection{Change of Higher Education in Taiwan}

Higher education in Taiwan confronts higher competition than before. Three challenges are analyzed to influence the sustainability of domestic colleges and universities. The first challenge is low-birth rate. In this decade, Taiwanese demographic structure has changed drastically because the newborn population is getting decreasing. The statistic number released by the Ministry of the Interior in Taiwan indicated that the newborn population dropped from 0.32 million in 1991 to 0.19 million in 2009, which is 0.13 million short. This challenge impacts the society in many aspects. Higher education is suffering insufficient student source. The policy of increasing higher education institutions released in 1994 even worsens this situation. More colleges and universities join the competition of the domestic market. There are over 120 higher education institutions in Taiwan, which grows six times more than that of 2002. It is no doubt that college administrators struggle for survival.

Even though the number of the domestic universities and colleges is increasing, these higher education institutions are facing the positioning issue. Some of them originated from the vocational education institutions. After upgrading its status, they do not appropriately prepare with their positions, which can distinguish from the others. In addition, the public schools compete with the private sector. All higher educational institutions learn from each other to obtain all kinds of resource. Eventually, the diversity among the schools is getting blurred. The stereotype images of the higher education institutions in Taiwan can possibly mislead the choice of the students and parents when applying their target learning institutions.

In addition, the domestic higher education practitioners are not familiar with educational marketing. In general, the old approach was relatively passive. For example, some faculty and staff consider that promoting schools has nothing to do with them, but belongs to the specialists. Plus, not every college or university has a clear position. Therefore, it is very difficult to develop an effective marketing strategy. In the past, Taiwanese universities only focused on the ranking. That became the apparent feature for school promotion. However, the number of the higher education institutions is increasing. Promoting a college or university should go beyond this.

In order to develop more advantages for competition in faculty, students, financial resource and so on, mastering educational marketing becomes a critical leverage for current higher education practitioners in Taiwan. The concept of marketing applied to education across the world started from 1980s. This is a dynamic process to analyze, plan, implement and control educational programs to bring voluntary exchanges of values with target audience $[1,2,3]$. Unlike the traditional model of educational marketing, which assumed audience passively receive information relevant to tangible resource, embedded value, and transaction, the current approach emphasizes on value co-creation, long-term relationship, 
sustainable effectiveness, and loyalty [4]. The paradigm shift of education marketing turns brand orientation into the forefront of strategy and activities.

Nowadays marketing in higher education is suggested to well manage it brand [2]. A brand is associated with the attributes, benefits and attitudes which can influence purchase intentions. It takes many factors into account, such as learners' needs, market segmentation, competition, market positioning, service development and so on $[3,4$, 5]. A university brand can manifest institutional features to reflect its value and competency. With an appropriate brand of a university, the trust relationship with the stakeholders can be increased and the understanding of institutional development can be positive [6,7]. Many educational studies indicated that educational institution image is the center to promote its brand $[2,5,8,9]$.

Image refers to the attitudes individuals have for things or objects. They may not always be true due to individual subjective experiences or perspectives [10]. Image is not only used to distinguish from the others, but also benefit sustainability for creating values [11]. For business management, image is gradually considered as a kind of assets due to the prevailing concept of intelligence property [12]. Intelligence property comprises structural assets, human resource assets, relationship assets, and so on. Corporate image is subordinated to the structural assets.

Managing a college in a sense is like running a business. The stakeholders maintain intimate relationship with a school. It is no doubt that school image can influence the stakeholders' satisfaction and expectation [13]. Brand management is a critical notion which can apply to higher education management $[14,15,2]$. When dealing with college image assets, higher education institutions should expand their focus from tangible properties to intangible ones [16]. In addition to the facility, equipment, and environment, more aspects, such as competency, quality, service, and so on, should be put into consideration. Some studies tried to directly identify critical marketing factors, including physical environment, service employees, delivery process, administrative support, residence, media operation, professional experiences, and learning resources $[2,14,17]$. The relationship with the stakeholders in various stages was another perspective to discuss educational marketing for higher education $[2,6$, 18]. Besides, some scholars examined how higher educational institutions deal with branding via educational marketing tools $[3,14]$. These diverse experiences revealed the complexity of the practice of educational marketing. Also, the factors should be integrated as a whole, instead of isolated activities.

Struggling in a high competitive situation, the colleges and universities in Taiwan need to pursue distinguished features to maintain and expand their markets. A brand can project its own image, which can reveal the differences from the competitive products and influence purchase or use of clients. Taiwanese higher education institutions can obtain more competitive advantages by well communicating the school features, quality, and service with all the stakeholders. Therefore, how to identify the management factors of college image assets and optimize the operation process can provide practical assistance for the sustainability of these higher education institutions.

\subsection{Research Objectives}

Nowadays Taiwanese higher education is confronting many challenges which are more drastic than before. Effective image asset management of college image can benefit expanding the market and create more values for sustainability. The college image assets comprise not only tangible, but also intangible resource. The better image a college can creates, the more advantages can be obtained. Therefore, this study aimed to identify effective factors influencing college image management, and explore how the college administrators configure them in promotion and marketing. The below are the objectives:

A Identify the factors influencing college image management.

B Construct a management framework of college image assets.

C Rank the criteria of a college image management framework.

\section{Methods}

Two research methods were implemented to achieve this study, which comprised the modified Delphi method and analytic hierarchy process (AHP). The modified Delphi method aimed to identify the critical factors in a systematic framework, while AHP provided the weights of each factors evaluated by the higher education institution workers.

\subsection{Modified Delphi Technique}

Originally, the Delphi technique was proposed by the RAND Corporation in 1950's. Now this method is accepted not only in America, but globally. This technique can obtain the consensus among a group of reliable experts, which can be used to identify and prioritize managerial issues or strategic actions [19]. The Delphi technique has proven a popular tool in many fields, such as business, information technology, engineering, health care, education, and so on [20].

Facilitating an interactive communication process among a group of experts is how the Delphi technique collects and organizes the opinions on specific issues or problems. The experts discuss and exchange the opinions on problems, solutions, plans, or opportunities by distributing a series of questionnaires among them. The results of the previous questionnaire are organized to modify the subsequent run. The process only stops when the experts reach their consensus [21]. Four features of the 
Delphi method was characterized [22]:

A The participants are anonymous.

B The process is iteration.

C Feedback stimulates input.

D The responses can be qualitatively analyzed.

Even though the Delphi technique has its advantages, conducting a study with this method can be very time-consuming. In particular, while a large number of experts are involved in discussing and exchanging by questionnaires, the process can take more time than expected [23]. The modified Delphi technique is adapted from the Delphi technique. These techniques are similar in terms of procedure and intention. The modified one starts with a set of selected items or factors which are identified from various sources, such as related profiles, literature, and other expert reviews. This modification provides a solid ground for discussion and brings the focus for the initial run of group discussion. In addition, the modified Delphi can reduce the bias caused in recurring discussion by assuring anonymity of the experts [24].

In this study, five scholars and experts from the fields of education and communication were recruited for the modified Delphi discussion. A survey was developed based on related literature which benefited the participants focusing on the selected criteria. The group discussion was arranged from March to June, 2016, which had finally reached the consensus after two runs of distant opinion exchange. Five participants reviewed and revised this survey in terms of semantic expression. Meanwhile, the selected factors were examined for the consistency and effectiveness. At last, the criteria were broken down into three layers: dimensions, sub-dimensions, and indicators, which created a systematic framework for all the factors of college image assets management.

\subsection{Analytic Hierarchy Process (AHP)}

Analytic hierarchy process (AHP) was developed by Thomas Satty in 1971, which was designed to optimize making decisions, developing strategies, or selecting actions. A contemporary challenge to management is dealing with complicated factors, including qualitative or quantitative [25]. The factors have mutual influence on each other in the process of choice option for managers. How to setting up priorities for the alternatives and select the optimized choice is a contemporary management challenge [26]. In order to reach an effective decision, it is critical to find a simplified way to measure the impacts of the factors. AHP can contribute to managers by categorizing the factors into a hierarchical structure and derives ratio scales to the factors by pairing them for comparison [27].

It is found in many fields that AHP is applied for prioritizing factors and requirements, choosing among strategies, estimating cost, selecting collaborative vendors, or assessing quality of action plans $[28,29]$. That shows the functions of this technique in terms of reducing risks of making wrong decision as well as selecting the best choice by measuring the possible impacts of the options.

Three steps are involved in implementing AHP: developing the hierarchy of criteria, analyzing criterion priority, and verifying the consistency [28]. First, AHP develops a hierarchical structure which comprises multiple criteria breaking down from the options or problems. Next, the participative experts start pair comparison of each component of a specific criterion in the same level. The score is assigned to each component after experts' determination. In order to assure the degree of consistency of experts' determination, AHP computes the consistency ratio of the pair comparisons. If the degree of consistency ratio reaches the limit, the experts have to revise the pair comparisons by reviewing the data. AHP cannot complete the priority ranking until the consistency ratio is checked.

AHP served this study for ranking the management indicators of college image assets. Between July and September, 20016, 25 AHP questionnaire were delivered to the higher education practitioners in Taiwan. The participants included higher- and middle-levels administrators as well as the campus staff in charge of PR and the related tasks. In order to expand the investigation, those participants did not only belong to the public universities, but also in the private sectors. 15 participants were from the public universities, while the 10 participants were from the private schools.

\section{Results}

The findings came from the results of the modified Delphi technique and analytic hierarchy process. The selected factors influencing college image management were form a three-layer framework. There were 5 dimensions, 13 sub-dimensions, and 77 indicators.

\subsection{Factors Identification}

After summarizing the literature of image management, it was found that brand management theory, corporate identity system (CIS), and customer satisfaction theory were often involved [30, 31, 32, 33].

According to literature [34, 35], Brand management is a dynamic process, which aims to strategically enhance the values of brand assets and ultimately improve institutional images. Brand management can create a dynamic balance between enterprises and the public through their visions, organizational culture, and images. This theory can apply to the field of higher education, which can explore how all stakeholders are engaged and influence the process of college image management. The stakeholders do not refer to students, faculty and staff, but also those who are off-campus, such as parents, alumni, community workers, and so on.

Corporate identify plays a critical role to corporate 
communication and marketing, which can be considered as a strategic management for an organization. Through corporate identity, an organization can communicate their integrated image to customers [36]. It cannot be only designed visually, but also can be presented in concepts and behaviors [37]. Identify design definitely influences the corporate's image for internal and external stakeholder. Appropriate design and communication through corporate identity can build a positive relationship with stakeholders, and so is for higher education institutions.

Nowadays, higher education institutions are influenced by business management in a sense. Students play a critical role to the sustainability of school management. On the other hand, the overall all images of schools influence students' involvement and satisfaction [13]. Therefore, higher educational institutions cannot neglect to maintain the relationship with students if they try to enhance their images.

Five categories of the factors can be identified based on the literature above. In this study, the first category was identified from the school image, which could refer to the attributes, awareness, and cognitive association of a school.
The second category was the identity of a school, which could be converted from the visions and principles of school management. It comprised visual, behavioral, and conceptual symbols and notions. The third category was related to PR operation by a school, which benefited the relationship between a school and the stakeholders. The last two categories of the factors were related to students and the rest stakeholders. The student category included current students and alumni, while the stakeholders comprised faculty and staff, the external participants.

\subsection{Indicator Configuration}

Two runs of the modified Delphi surveys were conducted among five scholars who were respectively from education and communication fields. The experts went through the selected factors from the literature and provided comments and feedback for revision. After organizing the suggestions and feedback, five experts reached their consensus with the three-layer college image asset management system. The following table reveals the first two layers of this system:

Table 1. The ranking of the college image asset management indicators

\begin{tabular}{|c|c|c|}
\hline Dimension & Sub-dimension & Conceptual definition \\
\hline \multirow{2}{*}{ College Brand } & Brand Awareness & $\begin{array}{l}\text { The strong level of a college brand that stakeholders perceive through their understanding, } \\
\text { identifying, and memorizing. }\end{array}$ \\
\hline & Brand Image & $\begin{array}{l}\text { Any information derived from a college brand perceived and associated by stakeholders, } \\
\text { which is based all kinds of service, symbols, features of a college. }\end{array}$ \\
\hline \multirow{3}{*}{$\begin{array}{l}\text { Identification } \\
\text { Strategy }\end{array}$} & Conceptual Id. & The visions and goals of a college developed by the administrators. \\
\hline & Behavioral Id. & $\begin{array}{l}\text { A series of communication, contact and interaction developed by college administrators to } \\
\text { deliver and enhance college visions and goals to their stakeholders. }\end{array}$ \\
\hline & Visual Id. & $\begin{array}{l}\text { The system of visual symbol developed by college administrators to materialize college } \\
\text { images. }\end{array}$ \\
\hline \multirow{4}{*}{ PR Operation } & $\begin{array}{l}\text { Stakeholder Database } \\
\text { Management }\end{array}$ & Managing and updating correct information of all stakeholders in a specific database. \\
\hline & PR Strategy Operation & $\begin{array}{l}\text { PR specialists of colleges conduct a series of marketing plans and actions to enhance } \\
\text { interaction and communication with stakeholders. }\end{array}$ \\
\hline & Crisis Management & $\begin{array}{l}\text { A series of crisis management procedures and actions in different phases developed by a } \\
\text { college. }\end{array}$ \\
\hline & $\begin{array}{l}\text { PR Effect Feedback } \\
\text { \&Evaluation }\end{array}$ & $\begin{array}{l}\text { Conducting survey or research to explore the effectiveness of crisis management that a } \\
\text { college confronts, so that the PR strategy can be revised based on feedback. }\end{array}$ \\
\hline \multirow[b]{2}{*}{ Student Image } & Student Satisfaction & The satisfaction level that all students perceive from all service provided by a college. \\
\hline & Alumni Loyalty & $\begin{array}{l}\text { The positive attitudes and behavior that graduated students have for a college after } \\
\text { graduation. }\end{array}$ \\
\hline \multirow[b]{2}{*}{ Stakeholder Image } & $\begin{array}{l}\text { Internal Stakeholder } \\
\text { Image }\end{array}$ & $\begin{array}{l}\text { Internal stakeholder image refers to the positive feelings that faculty and staff perceive after } \\
\text { engaging in a campus. }\end{array}$ \\
\hline & $\begin{array}{l}\text { External Stakeholder } \\
\text { Image }\end{array}$ & $\begin{array}{l}\text { External stakeholder image refers to the positive feelings that those from off-campus } \\
\text { perceive after interacting with a campus. They are parents, prospective students, } \\
\text { community members, education officers, and so on. }\end{array}$ \\
\hline
\end{tabular}

In addition to the two layers, this system also comprised the third layer: indicators. These indicators were derived from the sub-dimensions of this system with specific operation definitions. Each indicator corresponded to a specific condition or issue of college image management. Implementing these indicators could illustrate to what degree a dimension and sub-dimension has been achieved for a college. In this study, the indicators were selected based on the scores evaluated by the scholars, which had to reach average 4.0, mode 5.0, standard deviation less than 1, and quartile deviation less than 0.5. In total, 77 indicators were identified respectively assigning to 13 sub-dimensions. 


\subsection{Priority Ranking}

According to the AHP questionnaires returned by the participants, the results showed that the values of C. R. and C. I. were less than 0.1 . It proved that the participants agreed with the indicators in all three levels. The priority ranking was revealed in the below:

Table 2. The ranking of the college image asset management indicators

\begin{tabular}{|c|c|c|c|c|c|}
\hline Dimension & Dim. Weight & Sub-dimension & Sub-dim. weight & Overall weight & $\begin{array}{l}\text { Overall } \\
\text { ranking }\end{array}$ \\
\hline \multirow{2}{*}{ College Brand } & \multirow{2}{*}{.183} & Brand Awareness & .285 & .052 & 10 \\
\hline & & Brand Image & .715 & .131 & 2 \\
\hline \multirow{3}{*}{ Identification Strategy } & \multirow{3}{*}{.158} & Conceptual Id. & .451 & .071 & 6 \\
\hline & & Behavioral Id. & .383 & .061 & 9 \\
\hline & & Visual Id. & .166 & .026 & 13 \\
\hline \multirow{4}{*}{ PR Operation } & \multirow{4}{*}{.217} & Stakeholder Database Management & .163 & .036 & 12 \\
\hline & & PR Strategy Operation & .303 & .066 & 8 \\
\hline & & Crisis Management & .314 & .068 & 7 \\
\hline & & PR Effect Feedback \&Evaluation & .219 & .048 & 11 \\
\hline \multirow{2}{*}{ Student Image } & \multirow{2}{*}{.208} & Student Satisfaction & .528 & .110 & 3 \\
\hline & & Alumni Loyalty & .472 & .098 & 4 \\
\hline \multirow{2}{*}{ Stakeholder Image } & \multirow{2}{*}{.234} & Internal Stakeholder Image & .649 & .152 & 1 \\
\hline & & External Stakeholder Image & .351 & .082 & 5 \\
\hline
\end{tabular}

Regarding to the dimension level, the results indicated that the "stakeholder image" overtook the other dimensions, followed by the "PR operation" and "student image" dimensions. However, these weight scores among these three dimensions were close. Overall speaking, this study claimed that college image assets management should prioritize the stakeholder image at first.

Next, the ranking of each sub-dimension was illustrated. In the category of college brank, "brand image" surpassed "brand awareness". In the category of identification strategy, "conceptual identification" was considered the most important, while "visual identification" was placed at the last. Four sub-dimensions were identified in the category of PR operation. The priority ranked from "crisis management", "PR strategy operation", "PR effect feedback and evaluation" to "stakeholder database management". In terms of the category of student image, "student satisfaction" overran "alumni loyalty". In the last category, stakeholder image, the internal stakeholder image was ranked higher than the external one.

The ranking indicated that the stakeholder image dimension was considered more important than the others, because the top four sub-dimensions were all related to the stakeholder image. The fact encourages that higher education practitioners should continue putting efforts to the external stakeholder (students, faculty and staff) as well as the external stakeholders. It echoes the trend of student-orientation in the higher education field.

Another suggestion from this study was that the higher education institutions need to augment their brand images over brand awareness. Polishing the campus features can contribute to institutional promotion. The marketing strategy seems more effective and convincing when the promotion focus is placed on the satisfaction and involvement from the external and internal stakeholders.

\section{REFERENCES}

[1] Sichaie, K. \& Morphew, C. C. (2014). What college and university websites reveal about the purposes of higher education. The Journal of Higher Education, 85(4), 499-530.

[2] Khanna, M., Jacob, I. \& Yadav, N. (2014). Identifying and analyzing touchpoints for building a higher education brand. Journal of Marketing for Higher Education, 24(1), 122-143.

[3] Filip, A. (2012). Marketing theory applicability in higher education. Social and Behavioral Sciences, 46(2012), 912-916.

[4] Judson, K. M.\& Taylor, S. A. (2014). Moving from marketization to marketing of higher education: the co-creation of value in higher education. Higher Education Studies, 4(1), 51-67.

[5] Stimac, H. \& Simic, M. L. (2012). Competitiveness in higher education: a need for marketing orientation and service quality. Economics \& Sociology, 5(2), 23-34.

[6] Oluseye, O. O., Tairat, B. T. \& Emmanuel, J. O. (2014). Customer relationship management approach and student satisfaction in higher education marketing. Journal of Competitiveness, 6(3), 49-62. 
[7] Woodall, T., Hiller, A. \& Resnick, S. (2014). Making sense of higher education: students as consumers and the value of the university experience. Studies in Higher Education, $39(1), 48-67$

[8] Casidy, R. (2013). The role of brand orientation in the higher education sector: a student perceived paradigm. Asia Pacific Journal of Marketing and Logistics, 25(5), 803-820.

[9] Kalimullina, A. M. \& Dobrotvorskaya, S. G. (2016). Higher education marketing strategies based on factors impacting the enrollees' choice of a university and an academic program. International Journal of Environmental \& Science Education, 11 (13), 6025-6040.

[10] Kotler, P. (2001). A Framework for Marketing Management. New Jersey: Prentice-Hall, Inc.

[11] Lewi, G. (2003).Les marques mythologies du quotidien: Comprendre le success des grandes marques. Paris: Village Mondial.

[12] Stewart, T.A. (1997) Intellectual capital: The new wealth of organization. London, Nicholas Brealey.

[13] Palacio, A. B., Meneses, G. D., \& Perez, P. J. P. (2002). The configuration of the university image and its relationship with the satisfaction of students. Journal of Educational Administration, 40(5), 486-505.

[14] Alipour, M., Aghamohammadi, A., Ahmadi, R., \& Hoseini, S. H. (2012). A new educational marketing mix: the 6 ps for private school marketing in Iran. Research Journal of Applied Sciences, Engineering and Technology, 4(21), 4314-4319

[15] Temple, P. (2006). Branding higher education: Illusion or reality? Perspectives, 10(1), 15-19.

[16] Lapovsky, L., McKeown-Moak, M. P., \& Spitz, W. T. (1999). Roles and Responsibilities of the Chief Financial Officer: New Directions for Higher Education, Jossey-Bass NACUBO, Retrieved May 15, 2005, from http://www.nacubo.org/x39.xml.

[17] Fagerstrom, A. \& Chinea, G. (2013). Co-creation of value in higher education: using social network marketing in the recruitment of students. Journal of higher education policy and management, 35(1), 45-52.

[18] Kalimullina, A. M. \& Dobrotvorskaya, S. G. (2016). Higher education marketing strategies based on factors impacting the enrollees' choice of a university and an academic program. International journal of environmental and science education, 11(13), 6025-6040.

[19] Okoli, C., \& Pawlowski, S. D. (2004). The Delphi method as a research tool: An Example, design considerations and applications. Information \& Management, 42(1), 15-29.

[20] Uhl, N. P. (1990). Evaluation model and approaches- Delphi technique. In Walberg, H. J., \& Haertal, G. D., The international encyclopedia of educational evaluation. Oxford, Pergamon.

[21] Skulmosk, G. J., Hartman, F. T., \& Krahn, J. (2007). The
Delphi method for graduate research. Journal of Information Technology Education, 6. 1-21

[22] Rowe, G. \& Wright, G. (1999). The Delphi technique as a forecasting tool: Issues and analysis. International Journal of Forecasting, 15(4), 353 - 375.

[23] Hsu, C. C., \& Standford, B. A., (2007). Delphi technique. Practical Assessment, Research and Evaluation, 12 (10), $1-8$

[24] Custer, R. L., Scarcella, J. A., \& Stewart, B.R. (1999). The modified Delphi technique - A rotational modification. Journal of Vocational and Technical Education, 15 (2).

[25] Liu, F. H., \& Hai, H. L. (2005). The voting analytic hierarchy process method for selecting supplier. International Journal of Production Economics, 97 (2005), 308-317.

[26] Bhushan, N. and Ria, K. (2004) Strategic Decision Making: Applying the Analytic Hierarchy Process, London: Springer-Verlag London Limited.

[27] Saaty T. L. (2008). Decision making with the analytic hierarchy process. International Journal of Services Sciences, 1(1), 83-98.

[28] Ho, W. (2008). Integrated analytic hierarchy process and its applications: A literature review. European Journal of Operational Research, 186 (2008), 211-228.

[29] Teknomo, K. (2006), Analytic Hierarchy Process (AHP) Tutorial, Retrieved from http://people.revoledu.com/kardi/tutorial/AHP/

[30] Aaker, D. A. (1991). Managing brand equity. New York: Free.

[31] Biel, A. L. (1992). How brand image drives brand equity. Journal of Advertising Research, 32.

[32] David, W. S. Tai, Wang, W. C., \& Huang, C. E. (2007). The correlation between school marketing strategy and the school image of vocational high schools. The Business Review, Cambridge. 8(2), 191-197.

[33] Keller, K. L. (1993). Conceptualizing, measuring and managing customer-based brand equity. Journal of Marketing, 57(1), 1-22.

[34] Aaker, D. A., \& Joachimsthaler, E. (2009). Brand leadership: Building assets In an information economy. Free Press, New York.

[35] Gylling, C., \& Lindberg-Repo K. (2006). Investigating the links between a corporate brand and a customer brand. Brand Management, 13 (4/5), 257-267.

[36] Balmer, J. M. T. \& Gray, E. R. (2000). Corporate identity and corporate communications: Creating a competitive advantage. Industrial and Commercial Training, 32(7), 256 -262 .

[37] Balmer, J. M.T. (2001). Corporate identity, corporate branding and corporate marketing: Seeing through the fog. European Journal of Marketing, 35(3/4), 248-291. 